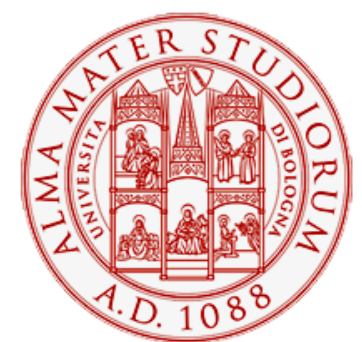

Alma Mater Studiorum - Università di Bologna DEPARTMENT OF ECONOMICS

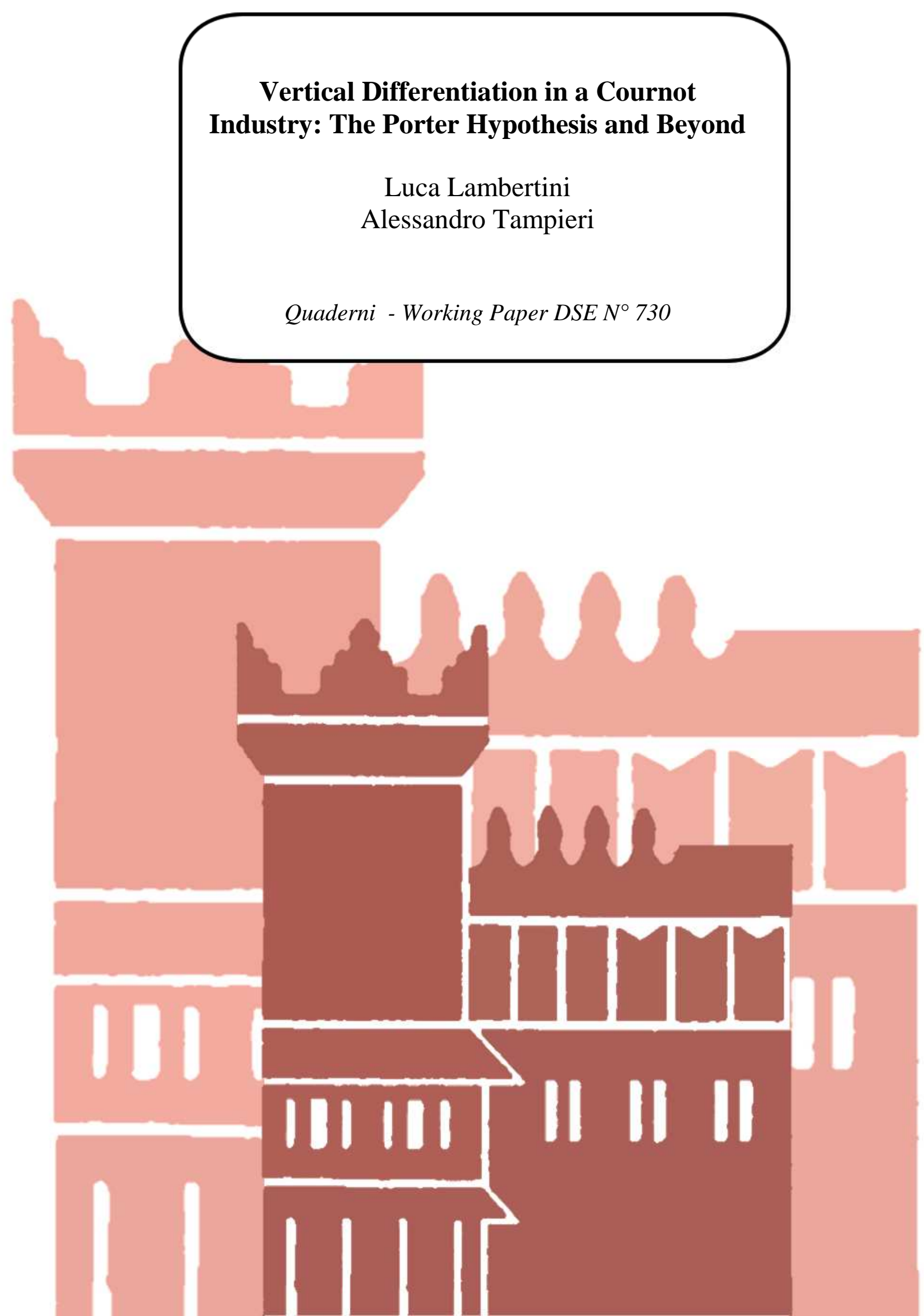




\title{
Vertical Differentiation in a Cournot Industry: The Porter Hypothesis and Beyond*
}

\author{
Luca Lambertini ${ }^{\S} \#$ and Alessandro Tampieri ${ }^{\S}$ \\ $\S$ Department of Economics, University of Bologna \\ Strada Maggiore 45, 40125 Bologna, Italy \\ luca.lambertini@unibo.it; alessandro.tampieri@unibo.it \\ \# ENCORE, University of Amsterdam \\ Roetersstraat 11, WB1018 Amsterdam, The Netherlands
}

February 11, 2011

\begin{abstract}
We modify the vertically differentiated duopoly model by André et al. (2009) replacing Bertrand with Cournot behaviour to show that firms may spontaneously adopt a green technology even in the complete absence of any form of regulation.
\end{abstract}

JEL codes: L13, L51, Q55, Q58

Keywords: environmental quality, quantity competition, green technology

${ }^{*}$ We would like to thank HERA Spa for sponsoring this project. The usual disclaimer applies. 


\section{Introduction}

The Porter Hypothesis (Porter, 1990, 1991) challenges the view according to which any form of environmental regulation necessarily hinders firms' profit perspectives. Indeed, according to Porter, environmental regulation may induce efficiency and encourage innovations.

Several contributions nested in the debate triggered by this claim have brought to the fore a number of scenarios where the Porter Hypothesis may apply (see Porter and van der Linde, 1995; Simpson and Bradford, 1996; Xepapadeas and de Zeeuw, 1999; and Hart, 2004). In particular, André et al. (2009) support the Porter Hypothesis by arguing that, in a vertically differentiated duopoly with Bertrand competition, where firms can decide whether to invest in green $\mathrm{R} \& \mathrm{D}$ or not, it is possible to drive the industry to an equilibrium where both firms choose to adopt the green standard in presence of a streamlined regulation taking the form of a lump-sum tax levied on the brown technology.

Here, we extend the analysis carried out by André et al. (2009) assuming Cournot competition between firms at the market stage. The issue of why and when firms choose to be quantity- or price-setting agents has been lively discussed in the theory of industrial organization, pointing out that price (respectively, quantity) competition fits best industries where firms' capacity constraints are absent or loose (resp., tight). ${ }^{1}$ This appears to be the case, e.g., in the car industry, where a firm's plant size matters. Additionally, this is a prototypical market where the environmental implications of production are relevant, and the existence of appropriate incentives for investments aimed at the attainment of green product qualities is a hot issue. In fact, casual

\footnotetext{
${ }^{1}$ As is well known, the first analysis of capacity-constrained price competition is in Edgeworth (1897). In the modern literature, see Beckman (1967); Levitan and Shubik (1972); Kreps and Scheinkman (1983); Singh and Vives (1984); Osborne and Pitchik (1986), to mention only a few.
} 
observation suggests that several large firms like Honda, Toyota and VWAudi are investing (or are about to invest) massive resources in $R \& D$ for clean technologies, without being subject to a specific form of taxation on any brown technology currently in use, which are instead regulated through minimum quality standards (like Euro V). Hence, one is led to think that these efforts must be driven by profit incentives largely - if not altogether independent of the regulatory framework.

This is precisely the bottom line of our analysis. By replacing Bertrand with Cournot, the resulting softer competition at the market stage delivers the appropriate incentives for firms to standardise the industry onto the green product, in absence of any regulation whatsoever. This opens a perspective that stretches even beyond the Porter Hypothesis, prompting for the investigation of scenarios where firms governed by unconstrained profit incentives may pursue projects ultimately leading to socially efficient outcomes.

\section{The model}

We adopt largely the same setup as in André et al. (2009). We describe a vertically differentiated duopoly under complete information, where singleproduct firms, 1 and 2, decide whether to supply a high- or low-quality good, identified by $q_{H}>q_{L}$. Quality has both hedonic and environmental features; in particular, while $q_{L}$ involves some undesirable environmental externality, i.e., it is brown, while $q_{H}$ is green. the individual firm's profit function is

$$
\pi_{i j}=\left(p_{i j}-c x_{i j}\right) x_{i j}, \quad i, j=H, L
$$

where $x_{i j}$ indicates the output level of firm $i$ (hence, in the remainder the first subscript will consistently refer to firm $i$ while the second will refer to the rival). As it appears from (1), the production technology involves variable 
costs, which are quadratic in the output level:

$$
C_{i j}=c x_{i j}^{2}, \quad c>0
$$

For the moment, we abstract from any fixed costs related to installed capacity or the $\mathrm{R} \& \mathrm{D}$ effort required for the attainment of either quality level. We will come back to this aspect of technology in the remainder. Similarly, we suppose that firms are not subject to any regulatory measure, unlike what appears in André et al. (2009), where firms pay a lump-sum tax when supplying the brown variety.

Using (1) we may describe three possible cases: either both firms supply the green (resp., brown) standard, so that consumers indeed purchase a homogeneous good, or they opt for different quality levels.

The demand side is as in Mussa and Rosen (1978) and Gabszewicz and Thisse (1979): there exists a continuum of consumers indexed by their marginal willingness to pay for quality $\theta \in[\underline{\theta}, \bar{\theta}]$, with $\underline{\theta}=\bar{\theta}-1$. The distribution of consumers is uniform, with density $f(\theta)=1$, so that the total mass of consumers is also equal to one. Each consumer buys at most one unit of variety $i=H, L$, whereby his net utility is either $U=\theta q_{i}-p_{i j} \geq 0$, or nil if he doesn't buy. As André et al. (2009), we focus on the case where the market is partially covered. The construnction of the demand system is best approached by considering first the case where firms supply different quality levels. If so, there exists a consumer who is indifferent between buying the low-quality good and not buying at all. His location along the spectrum of the marginal willingness to pay is given by the ratio $\widetilde{\theta}=p_{L H} / q_{L}$. Given generic prices and qualities, the location of the consumer indifferent between the two varieties is $\widehat{\theta}=\left(p_{H L}-p_{L H}\right) /\left(q_{H}-q_{L}\right)$, so that the system of direct market demands is $x_{H L}=\bar{\theta}-\widehat{\theta}$ and $x_{L H}=\widehat{\theta}-\widetilde{\theta}$. This is what one needs to 
use in order to model Bertrand behaviour, while inverse demands

$$
\begin{gathered}
p_{H L}=\left(\bar{\theta}-x_{H L}\right) q_{H}-q_{L} x_{L H} \\
p_{L H}=\left(\bar{\theta}-x_{H L}-x_{L H}\right) q_{L}
\end{gathered}
$$

are to be used under Cournot competition. If instead both firms adopt the same quality standard (either green or brown), demands (3) symmetrically collapse onto:

$$
p_{i i}=\left(\bar{\theta}-2 x_{i i}\right) q_{i}, \quad i=H, L .
$$

The interaction between firms is fully noncooperative and takes place in two stages. In the first, firms set their respective quality levels; then, in

the second, which is the proper market stage, they compete in outputs à la Cournot. The solution concept applied is the subgame perfect equilibrium by backward induction.

\section{The game}

To begin with, we have to solve the three possible Cournot subgames. The fastest way to do it is to focus on the case in which firms supply different standards. The first order conditions for profit maximization are:

$$
\begin{gathered}
\frac{\partial \pi_{H L}}{\partial x_{H L}}=\left(\bar{\theta}-2 x_{H L}\right) q_{H}-2 c x_{H L}-q_{L} x_{L H}=0 \\
\frac{\partial \pi_{L H}}{\partial x_{L H}}=\left(\bar{\theta}-x_{H L}-2 x_{L H}\right) q_{L}-2 c x_{L H}=0
\end{gathered}
$$

yielding:

$$
\begin{aligned}
x_{H L}^{*} & =\frac{\bar{\theta}\left[2 c q_{H}+\left(2 q_{H}-q_{L}\right) q_{L}\right]}{4 c\left(q_{H}+q_{L}+c\right)+\left(4 q_{H}-q_{L}\right) q_{L}} \\
x_{L H}^{*} & =\frac{\bar{\theta}\left(2 c+q_{H}\right) q_{L}}{4 c\left(q_{H}+q_{L}+c\right)+\left(4 q_{H}-q_{L}\right) q_{L}}
\end{aligned}
$$


The resulting Cournot-Nash profits are:

$$
\begin{aligned}
\pi_{H L}^{*} & =\frac{\bar{\theta}^{2}\left[2 c q_{H}+\left(2 q_{H}-q_{L}\right) q_{L}\right]^{2}\left(c+q_{H}\right)}{\left[4 c\left(q_{H}+q_{L}+c\right)+\left(4 q_{H}-q_{L}\right) q_{L}\right]^{2}} \\
\pi_{L H}^{*} & =\frac{\bar{\theta}^{2}\left(2 c+q_{H}\right)^{2} q_{L}^{2}\left(c+q_{L}\right)}{\left[4 c\left(q_{H}+q_{L}+c\right)+\left(4 q_{H}-q_{L}\right) q_{L}\right]^{2}}
\end{aligned}
$$

The alternative cases where firms symmetrically choose the same standard (either brown or green) obtain from (6-7) by imposing $q_{i}=q_{j}{ }^{2}$ This yields:

$$
\begin{aligned}
x_{i i} & =\frac{\bar{\theta} q_{i}}{3 q_{i}+2 c}, \quad i=H, L, \\
\pi_{i i}^{*} & =\frac{\bar{\theta}^{2} q_{i}^{2}\left(q_{i}+2 c\right)^{2}\left(c+q_{i}\right)}{\left[3 q_{i}^{2}+4 c\left(2 q_{i}+c\right)\right]^{2}}
\end{aligned}
$$

Before proceeding any further, it is worth oserving that

$$
\frac{\partial x_{i i}}{\partial q_{i}}=\frac{2 \bar{\theta} c}{\left(3 q_{i}+2 c\right)^{2}}>0
$$

entailing that total industry output is strictly higher when both firms adopt the green standard than when they adopt the brown one. The equilibrium price in the symmetric cases writes as follows:

$$
p_{i i}=\frac{\bar{\theta} q_{i}\left(2 c+q_{i}\right)}{3 q_{i}+2 c}, \quad i=H, L,
$$

with

$$
\frac{\partial p_{i i}}{\partial q_{i}}=\frac{\bar{\theta}\left[4 c^{2}+q_{i}\left(4 c+3 q_{i}\right)\right]}{\left(3 q_{i}+2 c\right)^{2}}>0
$$

so that switching from brown to green qualities brings about an increase in price. Therefore, a priori, if the whole industry increases the quality standard

\footnotetext{
${ }^{2}$ Under quantity competition, it is not necessary to build up the demand functions for the homogeneous good case as it is instead under Bertrand competition (see André et al., 2009, p. 185)
} 
symmetrically, the net effect on consumer surplus is ambiguous, depending upon the balance between the increase in quality and output on one side and the increase in price on the other.

In the general case where firms supply differentiated products, consumer surplus is:

$$
\begin{aligned}
C S_{i j} & =\int_{\tilde{\theta}}^{\hat{\theta}}\left(v q_{L}-p_{L H}\right) d v+\int_{\hat{\theta}}^{\bar{\theta}}\left(v q_{H}-p_{H L}\right) d v \\
& =\frac{q_{L} x_{L H}^{2}+x_{H L}\left(q_{H} x_{H L}+2 q_{L} x_{L H}\right)}{2}
\end{aligned}
$$

which, in the symmetric cases, becomes:

$$
C S_{i i}=\frac{2 \bar{\theta}^{2} q_{i}^{3}}{\left(3 q_{i}+2 c\right)^{2}}
$$

with

$$
\frac{\partial C S_{i i}}{\partial q_{i}}=\frac{6 \bar{\theta}^{2} q_{i}^{2}\left(q_{i}+2 c\right)}{\left(3 q_{i}+2 c\right)^{3}}>0
$$

On this basis, we can formulate:

Lemma 1 The symmetric switch from brown to green quality involves an increase in consumer surplus.

This of course is driven by the fact that the balance between the increase in all variables involved is such that consumers are happy to purchase larger amounts of the green variety even if this happens at a higher price.

We are now in a position to investigate the symultaneous choice of the quality level, either $H$ or $L$, by the two firms. As in André et al. (2009, p. 187), this is described by the reduced-form stage appearing in Matrix 1.

2

$$
\begin{array}{cc|l|l|}
\multicolumn{1}{c}{} & \multicolumn{1}{c}{H} & \multicolumn{1}{c}{L} \\
\cline { 3 - 4 } 1 & H & \pi_{H H}^{*} ; \pi_{H H}^{*} & \pi_{H L}^{*} ; \pi_{L H}^{*} \\
\cline { 2 - 4 } & L & \pi_{L H}^{*} ; \pi_{H L}^{*} & \pi_{L L}^{*} ; \pi_{L L}^{*} \\
\cline { 2 - 3 } & &
\end{array}
$$

Matrix 1 
The equilibrium analysis can be carried out by assessing the sign of three key inequalities involving the payoffs apeparing in Matrix 1. To begin with, consider the main diagonal, along which we have:

$$
\pi_{H H}^{*}-\pi_{L L}^{*} \propto 4 c\left(q_{H}+c\right)\left[c q_{H}+\left(c+3 q_{H}\right) q_{L}\right]+\left(2 c+3 q_{H}\right)^{2} q_{L}^{2}>0 .
$$

This establishes the superiority of the green standard in terms of the reuslting profit incentives for firms, the explanation being that the higher production costs associated with supplying the green standard rather than the brown one are more than compensated by the corresponding increase in market price generated by consumers' hedonic inclinations.

Then, we move on to consider the inequalities by rows or columns:

$$
\pi_{H H}^{*}-\pi_{L H}^{*} \propto 16\left(q_{H}+c\right)^{3}\left(q_{L}+c\right)-q_{H}^{2} q_{L}^{2}>0
$$

as $q_{H}^{3} q_{L}>q_{H}^{2} q_{L}^{2} ;$ moreover,

$$
\begin{aligned}
& \pi_{H L}^{*}-\pi_{L L}^{*} \propto\left[36 q_{H}+q_{L}\left(q_{L}-16\right)\right]+4 c\left[3\left(10 q_{H}-q_{L}\right) q_{L}^{3}+\right. \\
& \left.c\left(4 c\left(c\left(q_{H}+q_{L}\right)+q_{L}\left(5 q_{H}+3 q_{L}\right)\right)\right)+\left(37 q_{H}+9 q_{L}\right) q_{L}^{2}\right]>0
\end{aligned}
$$

since $36 q_{H}-16 q_{L}>0$.

Therefore, on the basis of the foregoing analysis, we can formulate the following claim:

Proposition 2 Pure profit incentives yield $(H, H)$ as the unique Nash equilibrium at the intersection of strictly dominant strategies, in absence of any form of regulation. The equilibrium outcome is also Pareto-efficient for firms.

That is, the stage game depicted in Matrix 1 is not a prisoners' dilemma. The source of the spontaneous alignement of firms on the green quality in an unregulated market is to be found in the less aggressive nature of Cournot behaviour as opposed to Bertrand. This ultimately makes the lump-sum tax appearing in André et al. (2009) redundant. 
Combining Proposition 2 with the additional facts that (i) consumer surplus is higher in $(H, H)$ than in $(L, L)$ - as we know from Lemma 1 - and (ii) the negative environmental externality curtailing welfare in $(L, L)$ disappears altogether in $(H, H)$, it is also true that

Corollary 3 Social welfare is higher in $(H, H)$ than in $(L, L)$.

The foregoing analysis can be generalised as follows. The result outlined in Proposition 2 clearly extends to the case where there exists a symmetric fixed cost $F$, and may indeed hold even in the more general case where developing either quality standard requires some $R \& D$ effort summarised in a quality-specific fixed cost $F_{K}, K=H, L$, with $F_{H}>F_{L}$. This can be easily appreciated by observing that the presence of quality-specific fixed costs modifies the equilibrium values of objective functions as follows:

$$
\widehat{\pi}_{i j}^{*}=\pi_{i j}^{*}-F
$$

whereby Proposition 2 applies provided that the inequalities

$$
\begin{aligned}
\widehat{\pi}_{H H}^{*}>\widehat{\pi}_{L L}^{*} & \Leftrightarrow \pi_{H H}^{*}-\pi_{L L}^{*}>F_{H}-F_{L} \\
\widehat{\pi}_{H H}^{*}>\widehat{\pi}_{L H}^{*} & \Leftrightarrow \pi_{H H}^{*}-\pi_{L H}^{*}>F_{H}-F_{L} \\
\widehat{\pi}_{H L}^{*}>\widehat{\pi}_{L L}^{*} & \Leftrightarrow \pi_{H L}^{*}-\pi_{L L}^{*}>F_{H}-F_{L}
\end{aligned}
$$

holds across the three admissible cases simultaneously. This can be summarised in:

Corollary 4 If $\min \left\{\pi_{H H}^{*}-\pi_{L L}^{*}, \pi_{H H}^{*}-\pi_{L H}^{*}, \pi_{H L}^{*}-\pi_{L L}^{*}\right\}>F_{H}-F_{L}$, then $(H, H)$ is the unique Nash equilibrium in strictly dominant strategies of the game, in presence of asymmetric fixed costs of quality improvement.

A straightforward addendum to the above Corollary is that, whenever $(H, H)$ is the equilibrium, then it remains also socially optimal. 


\section{Concluding remarks}

We have revisited the vertically differentiated duopoly model by André et al. (2009) under quantity-setting behaviour, to highlight the striking fact that softening market competition may have far-reaching consequences as far as the environmental performance of the industry is concerned. Indeed, our simple model is something more than a vindication of the Porter Hypothesis, as it shows that private and social incentives towards the adoption of green technologies may in fact be reciprocally aligned.

\section{References}

[1] André, F.J., González, P. and Porteiro, N. (2009). Strategic quality competition and the Porter hypothesis. Journal of Environmental Economics and Management 57: 182-194.

[2] Beckman, M. (1967). Edgeworth-Bertrand duopoly revisited, in Henn, R. (ed.), Operations Research-Verfahren, III, Meisenhein, Verlag Anton Hein.

[3] Edgeworth, F. (1897). La teoria pura del monopolio. Giornale degli Economisti 40: 13-31. Reprinted in English as: The pure theory of monopoly, in Edgeworth, F. (1925). Papers Relating to Political Economy, Vol. 1, London, Macmillan \& Co., Ltd., 111-142.

[4] Gabszewicz, J.J. and Thisse, J.-F. (1979). Price competition, quality, and income disparities. Journal of Economic Theory 20: 340-359.

[5] Hart, R. (2004). Growth, environment and innovation - a model with production vintages and environmentally oriented research, Journal of Environmental Economics and Management 48: 1078-1098. 
[6] Kreps, D. and Scheinkman, J. (1983). Quantity precommitment and Bertrand competition yield Cournot outcomes. Bell Journal of Economics 14: 326-337.

[7] Levitan, R. and Shubik, M. (1972). Price duopoly and capacity constraints. International Economic Review 13: 111-123.

[8] Mussa, M. and Rosen, S. (1978). Monopoly and product quality. Journal of Economic Theory 18: 301-317.

[9] Osborne, M. and Pitchik, C. (1986). Price competition in a capacityconstrained duopoly. Journal of Economic Theory 38: 238-260.

[10] Porter, M. (1990). The Competitive Advantage of Nations, Free Press, New York.

[11] Porter, M. (1991). America's green strategy. Scientific American 264: 96.

[12] Porter, M. and van der Linde, C. (1995). Toward a new conception of the environment-competitiveness relationship. Journal of Econonomic Perspectives 9: 97-118.

[13] Simpson, R.D. and Bradford, R.L. III (1996). Taxing variable cost: Environmental regulation as industrial policy. Journal of Environmental Economics and Management 30: 282-300.

[14] Singh, N. and Vives, X. (1984). Price and quantity competition in a differentiated duopoly. Rand Journal of Economics 15: 546-554.

[15] Xepapadeas, A. and de Zeeuw, A. (1999). Environmental policy and competitiveness: The Porter hypothesis and the composition of capital. Journal of Environmental Economics and Management 37: 165-182. 


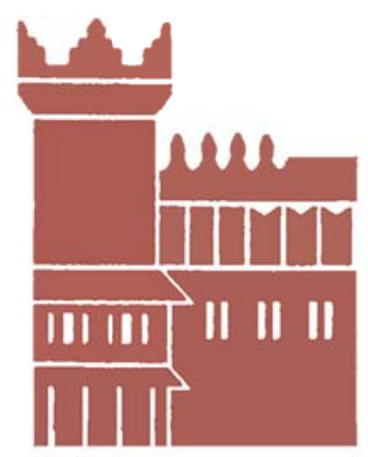

Alma Mater Studiorum - Università di Bologna DEPARTMENT OF ECONOMICS

Strada Maggiore 45

40125 Bologna - Italy

Tel. +39051 2092604

Fax +390512092664

http://www.dse.unibo.it 